\title{
In Honor of Dr. Abdul Hussein Taba: Iranian Physician and Former Director of the Eastern Mediterranean Region of the World Health Organization
}

\author{
Leila Mounesan, $\mathrm{MSc}^{1}$; Ehsan Mostafavi, $\mathrm{PhD}^{1^{*}}$
}

${ }^{1}$ Department of Epidemiology and Biostatistics, Research Centre for Emerging and Reemerging Infectious Diseases, Pasteur Institute of Iran, Tehran, Iran

\begin{abstract}
The honorable Abdul Hussein Tabatabaei was born in 1911 in Iran and received his medical education in the United Kingdom. Famously known as Dr. A.H. Taba, he was a well-respected man for his significant impact on the improvement of the national and global healthcare services and support for social justice. Before joining the World Health Organization (WHO), he was twice elected to the Iranian national assembly and served as the under-secretary of health services in Iran. Later, he joined the WHO and was elected as the Director of the Eastern Mediterranean Region (EMRO) in Alexandria in 1957 - a position he maintained for 25 years. During his tenure as the Regional Director, he rendered valuable assistance to the development and expansion of major health issues such as development and expansion of the health workforce, improvement of the national health services and controlling of various communicable diseases in the member countries and across the WHO regional offices.

Keywords: History of medicine, Iran, Malaria, Smallpox, World Health Organization

Cite this article as: Mounesan L, Mostafavi E. In honor of Dr. Abdul Hussein Taba: Iranian physician and Former Director of the Eastern Mediterranean Region of the World Health Organization. Arch Iran Med. 2020;23(10):707-711. doi: 10.34172/ aim.2020.90.
\end{abstract}

Received: July 7, 2020, Accepted: August 2, 2020, ePublished: October 1, 2020

\section{Life Story}

One of the great Iranian contemporary medical practitioners, Dr. Abdul Hussein Tabatabaei Naeini, generally known as Dr. A. H. Taba was born in 1911 in a well-known and scholarly family in Mashhad, Iran. He was the son of Mirza Morteza Gholi Khan Tabatabaei Naeini. His father was the custodian of the administrative organization of the Holy Shrine of Imam Reza (Astan Quds Razavi) (Figure 1). ${ }^{1-3}$

\section{Education}

After successful completion of primary education in Mashhad and secondary education in Servat High School in Tehran, he studied medicine at the University

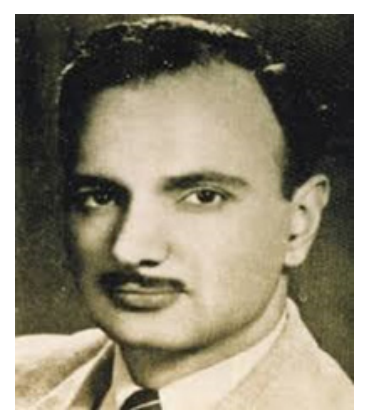

Figure 1. Dr. Abdul Hussein Taba Naeini. of Birmingham, UK, and received his medical degree in 1930. He received post-graduate degrees in medicine and surgery from the universities of London and Paris. Later in his professional life, he was elected as a fellow of the college of Physicians and Surgeons in Pakistan and was awarded an Honorary Fellowship in the Royal Society of Medicine in London in 1978. ${ }^{3,4}$

\section{Works in Iran}

Following his education in Europe, Dr. Taba returned to Iran in 1937, and began his required military service. He was posted as a physician for the Anglo-Iranian Oil Company (AIOC) in Abadan, Iran. This appointment lasted for four years after which he joined the Iranian Railways as a surgeon, and in 1949, he was appointed as the director of the railway health department in Tehran. ${ }^{3,5}$

In 1946, Dr. Taba was elected to the national assembly (Majlis) and functioned as the Chief of the Health Commission, a position he held till 1952. He was passionate about his work, and always had the welfare of the people in mind. ${ }^{2,3}$ Following his success, he was offered the position of the Minister of Health, but he refused.

At the time when the School of Public Health was established in Tehran University, Dr. Taba planned to give every year a scholarship for talented Iranian students to study one year in England or the USA. Based on this 
program, he supported several people. Dr. Abolhassan Nadim, the founder of modern epidemiology in Iran, was one of the supported people to study epidemiology in Chapel Hill, North Carolina, who trained enough epidemiologists in Iran after his return. ${ }^{6}$

\section{Work in World Health Organization}

Soon after joining the WHO, he was elected as the Deputy Director of Regional Office of the WHO Eastern Mediterranean Region (EMRO) in August 1952 and was stationed in Alexandria, Egypt. In January 1957, he was appointed as the Regional Director of "EMRO", a position he held for 25 , with the full support of the regional member states, as well as the Executive Board of the WHO. During his tenure as Regional Director, Dr. Taba served on various temporary positions such as the head of the Iranian delegation to the third, fourth and fifth World Health Assembly in Geneva, and the Vice-President of the 4th World Health Assembly and the 10th session of the WHO Executive Board. 4,5

As Regional Director, Dr. Taba was highly conscious of the needs of the member countries in the region and provided valuable assistance that resulted in considerable success in overcoming a high number of health problems such as control of some communicable diseases and environmental hazards. He was also interested in and effectively supported the trend in the Region towards the creation and promotion of essential capacities and public health services. ${ }^{7-9}$

Upon his retirement in the summer of 1982, in recognition of his brilliant activities, the Executive Board expressed its appreciation and paid special tribute to him for his work and support of the main health concerns and needs of the countries of the Region and introduced him as "WHO's most respected statesman, crucial in promoting a unified approach to world health problems" (Figure 2). ${ }^{4}$

\section{Activities in the Eastern Mediterranean Region}

During his time as the Regional Director, Dr. Taba spearheaded valuable measures for strengthening staff, infrastructure, policies, strategies and information with a focus on developing the health workforce and health services in the Region. Dr. Taba has been one of the main sources for the advancing of the primary health approach in the WHO. Furthermore, one of the assets of the EMRO during his tenure was the smooth running of the office that operated with speed and accuracy, even with the UN Bureaucracy.

He believed that community health, rural development, implementation of primary health care, health workforce development and health education of the general population were the main priorities for the region. Some of the services and health affairs that were implemented in all member countries of the region with Dr. Taba's leadership, support, and supervision are:

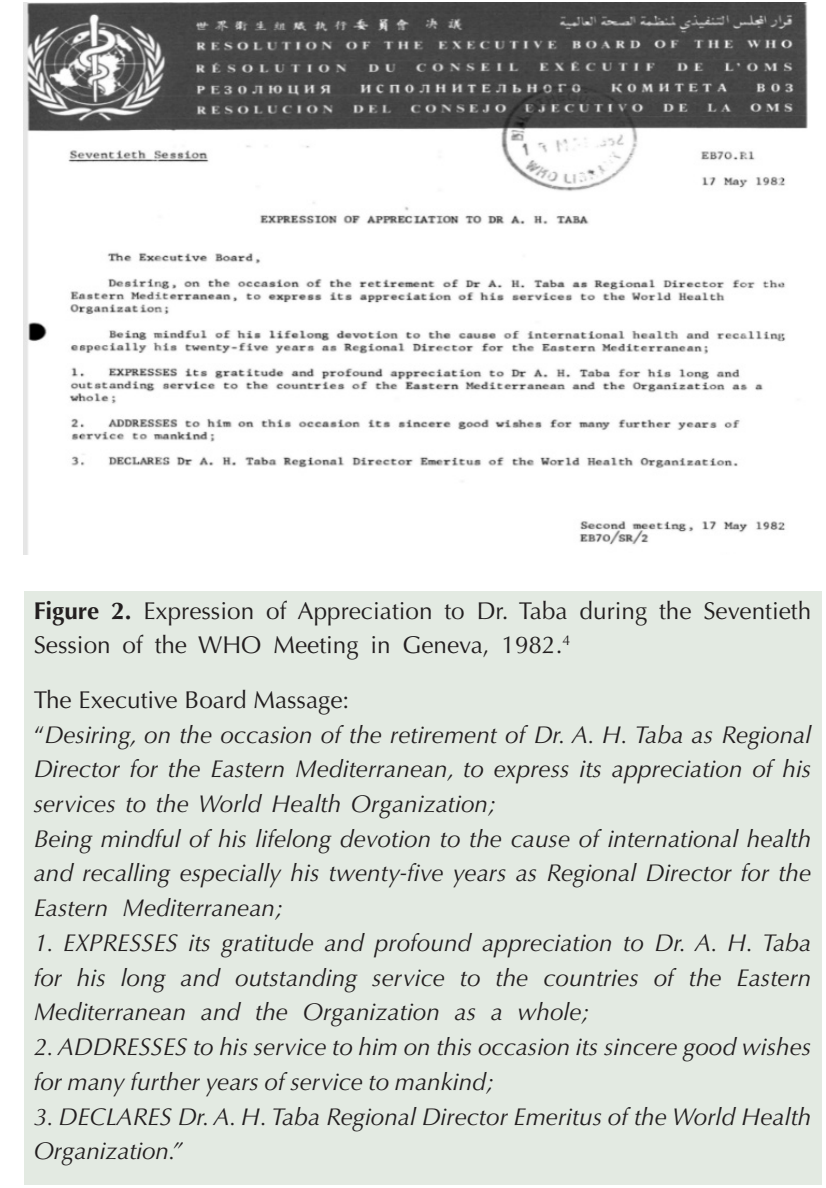

- Control of Malaria: As one of the major vector-borne diseases in the Region, Malaria was a top priority, and Dr. Taba assumed a leading role in organizing field operations to control and eradicate this disease in the region. Control efforts in each member country were tailored to follow the particular local circumstance. In Iran, the country was divided into four ecological zones, and the malaria eradication program was started in 1957. The program and operations were decentralized and were independently implemented in different provinces, under the overall supervision of the Scientific Council that was established at the Institute of Parasitology and Malariology at the University of Tehran that developed the technical plans and monitored its progress in collaboration with the Ministry of Health. Based on this program, 24500 villages with 6 million population were sprayed and surveillance operations were organized in about 13000 villages. Similar control measures were also implemented in other countries of the region such as Iraq, Jordan, Syria and Somalia. The malaria eradication programs were essentially divided into the direct and indirect control and protections measures that included anti-malarial campaigns and epidemiological surveys. As the success of these programs depended on supporting factors, notable activities were undertaken by conducting 
training courses, passing supporting legislations, securing financing and international cooperation, and organizing surveillance operations. Constant biological monitoring and regular assessment of the progress helped with early detection of problems such as resistance of some mosquito species to some insecticides such as DDT, as well as providing appropriate solutions. These overall approaches and supportive programs resulted in significant progress in malaria eradication programs. ${ }^{10,11}$

- Smallpox Eradication: Smallpox was a major global health problem and one of the most devastating diseases sweeping through the world in an epidemic form. Control efforts were taken from the beginning of the twentieth century; however, the commitment to global smallpox eradication was approved in 1958. At the EMRO, under the leadership of Dr. Taba, positive actions were undertaken, and various programs were planned and executed in many countries in the region which significantly helped with the achievement of global eradication of smallpox in $1977.8,12,13$

- Control of Schistosomiasis: Schistosomiasis was another endemic disease with significant health problems in the Region, which Dr. Taba was interested in and initiated specific control in countries in the member countries. The major contributing factor for this parasitic disease is lack of adequate sanitation and access to safe drinking water. The first control program for schistosomiasis was started in 1959 in Dezful, Iran, with the support and technical assistance of the EMRO. Similar support was also provided to several countries of the region with the same problem, including Sudan, Yemen, Saudi Arabia, Somalia, Jordan, Oman and Syria. These efforts resulted in reducing the infection rate in most countries and the elimination of the infection in Iran and Saudi Arabia. ${ }^{8,14}$

- Control of Diarrheal Diseases: Cholera, as an acute diarrheal disease, poses a significant threat to communities and can be deadly if left untreated. To achieve acceptable measures to curb the cholera outbreaks and to prevent further possible episodes, the Regional Office under the leadership of Dr. Taba, developed a specific mandate to assist member states in the formulation and implementation a unified health policy. In this regard, epidemiological methods were utilized to draw a full picture of the situation, including the nature of the etiological agents and its transmission, therapeutic approaches, and development of mechanisms to control the problem in the region. In the case of localized outbreaks, anti-cholera vaccination was carried out to control the situation. ${ }^{15-18}$ As a result, many countries in the EMRO achieved significant success in this fight during the 1970s and 1980s. Thus, diarrheal diseases are no longer considered to be a significant health problem in the Region. ${ }^{19-21}$

- Programs on Non-Communicable Diseases: Cancers became a major concern affecting member countries in the EMRO while Dr. Taba was in office. The first advisory panel on cancer in the Region was organized in Alexandria in February 1975. Along with that, remarkable developments occurred in the field of cancer detection, registration, and treatment by providing medium-term programs, conducting regional and international courses and establishing regional collaborating centers. Most prominent cancer activities were situation analysis of cancer in the region, the development of cancer services in the EMRO, screening programs in high-risk groups, and assessing risk and protective factors including socioeconomic factors. ${ }^{22}$

- Health Education Services: Health education programs, as a major and essential component of the EMRO, were implemented by holding numerous meetings, seminars and workshops at the Regional office in Alexandria and individual member countries according to their educational needs (Figures 3A3D). ${ }^{23-26}$ Dr. Taba also worked to improve medical education in the EMRO. As an example, he initiated the development of the Regional Office for Training Medical Educators and provided consultants for medical education in schools of medicine in most of the member countries. He arranged the visit of deans of schools of medicine of Iran to Mexico, the United States, Germany and Israel where methods of problem-solving and primary health care approaches were used. Furthermore, training courses and meetings were designed for a wide range of topics to improve the primary health care system in the member states, ${ }^{27}$ to extend the scientific and methodological approach for educational planning and curriculum design, ${ }^{28}$ to implement and evaluate the educational programs, ${ }^{29}$ to manage research projects by scientific methods on the utilization of network planning, ${ }^{30}$ to provide opportunities for teamwork at the community level, to assess the feasibility of utilizing field training experience of health care workers, ${ }^{31}$ to meet nursing demands and establish criteria for field practice, ${ }^{32}$ to promote the women and children's health status, ${ }^{33,34}$ to expand the immunization programs to six vaccinepreventable diseases; tuberculosis, diphtheria, pertussis, tetanus, measles and poliomyelitis, ${ }^{35}$ and to pay more attention to mental health and psychiatry. ${ }^{36}$

\section{Publications}

Dr. Taba published several articles on various aspects of health issues and medical education in the region, including evaluation of public health problems, ${ }^{37}$ and health education services ${ }^{38}$ in the region. He also published a few 

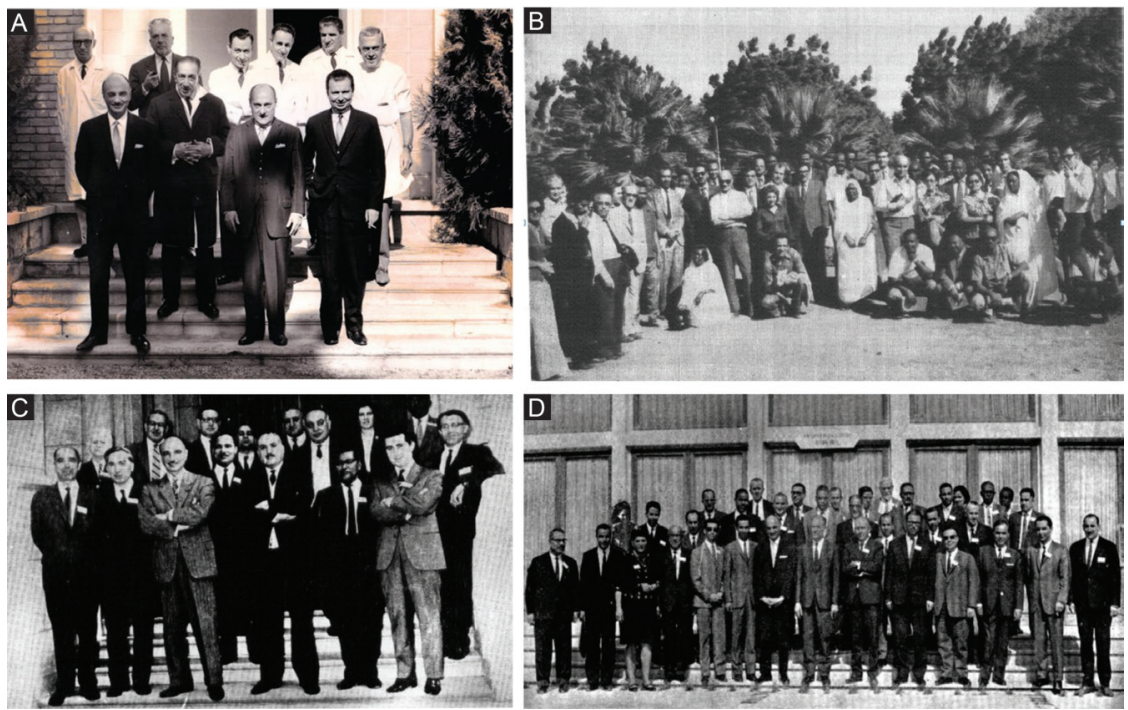

Figure 3. (A) Advisory Committee on Cholera, Pasteur Institute of Iran. On the first row from the left: Dr. Taba, Dr. Mehdi Ghodsi (Director of Pasteur Institute of Iran), Dr. Marcolino Gomes Candau (Director- General of WHO), Dr. Shah Gholi (Iran Minister of Health), 1965. ${ }^{23}$ (B) Seminar on the Training and Utilization of Medical Assistants, in Khartoum. Dr. Taba, with a glass standing, left center of the picture, $1974 .{ }^{24}$ (C) WHO Group Meeting on Medical Research Held in Alexandria. Dr. Taba is the third person from left on the first row, 1966..$^{25}$ (D) WHO Seminar on Health Services in Rural Areas Held in Tunis, Tunisia. Dr. Taba is the seventh person from left on the first row, $1968 .^{26}$

works on the activities and the structure of the EMRO. ${ }^{39-}$ ${ }^{42}$ Other topics of interest to him were the influence of irrigation on humanity, ${ }^{43}$ female circumcision, ${ }^{44}$ occupational carcinogenesis, ${ }^{45}$ and nutritional problems in the weaning period. ${ }^{46}$

Dr. Taba passed away in Geneva, Switzerland in 1982 and was buried there in the Grand Saconnex Cemetery.

\section{Authors' Contribution}

EM: Idea of the research. LM and EM: Collecting the data, drafting and finalizing the manuscript.

\section{Conflict of Interest Disclosures}

The authors report no conflicts of interest.

\section{Ethical Statement}

Not applicable.

\section{Acknowledgements}

We would like to thank Dr. Kiumarss Nasseri, Dr. Hossein MalekAfzali Ardakani, Dr. Fereydoon Arfaa, Dr. Abolhassan Nadim and Dr. Kiumars Khosh-Cheshm for their contribution in collecting more information about Dr. Taba.

\section{References}

1. Ehtesham Kavyanian M. Shams Al Shomoos or Tarikh Astan Quds. Astan Quds Razavi; 1969. [Persian].

2. Sajjadi Naeini M. Naein Balade Tayebeh. Isfahan: Kanoon Pazhoohesh; 2000. [Persian].

3. Naeini. Introducing the historical and tourist attractions of Naein. Brief biography of Dr. Abdul Hussein Taba. Available from: http://naeeni.com/drtaba/. Accessed october 2019. [Persian].

4. World Health Organization, Regional Office for the Eastern Mediterranean. Regional Director. Former Regional Directors. Available from: http://www.emro.who.int/about-who/ regional-director/former-regional-directors.html.

5. Magiran. Kayhan Newspaper. All Men Prime Minister. 2009. Available from: https://www.magiran.com/article/1920241.
Accessed October 2019. [Persian].

6. Mostafavi E, Haghdoost AA, Yavari P, Chaman R, Mesdaghinia A, Enayatrad M. Dr. Abolhassan Nadim, Founder of Modern Epidemiology in Iran. Iran J Epidemiology. 2018;13(4):264-72.

7. WHO News. News from the field. Am J Public Health. 1963; 53(10):1734-42. doi:10.2105/AJPH.53.10.1734.

8. WHO News. News from the field. Am J Public Health. 1962; 52(7):1219-27 doi:10.2105/AJPH.52.7.1219.

9. Health developments in the Eastern Mediterranean Region over 50 years. East Mediterr Health J. 1998;4(Suppl):S31-S57. Available from: https://apps.who.int/iris/handle/10665/118629.

10. World Health Organization. Thethirdtenyears of theWorld Health Organization: 1968-1977. 2008. Available from: https://apps. who.int/iris/bitstream/handle/10665/43924/9789241563666_ eng.pdf? sequence $=1$.

11. World Health Organization, Regional Office for the Eastern Mediterranean. Epidemiological aspects of malaria eradication in the Eastern Mediterranean Region. 1965. Available from: https://apps.who.int/iris/handle/10665/124069.

12. World Health Organization, Regional Office for the Eastern Mediterranean. Report on meeting of directors or representatives of schools of public health, Alexandria 13-17 October 1969. 1969. Available from: https://apps.who.int/iris/ handle/10665/254331.

13. World Health Organization, Regional Office for the Eastern Mediterranean. Minutes of the first meeting, held at the WHO Regional Office for the Eastern Mediterranean, Alexandria, Egypt, on Tuesday, 10 September 1974. 1974. Available from: https://apps.who.int/iris/handle/10665/120227.

14. Massoud J, Arfaa F, Farahmandian I, Ardalan A, Mansoorian A. Progress in the national schistosomiasis control programme of Iran. Bull World Health Organ. 1982;60(4):577-82.

15. World Health Organization, Regional Office for the Eastern Mediterranean. Rural health and community development in the Eastern Mediterranean Region, Results of an enquiry. 1962. Available from: https://apps.who.int/iris/ handle/10665/123382.

16. World Health Organization, Regional Office for the Eastern Mediterranean. Regional scientific working group meeting on diarrhoeal disease control, Amman, 11-14, 
June 1979. 1979. Available from: https://apps.who.int/iris/ handle/10665/254372.

17. World Health Organization, Regional Office for the Eastern Mediterranean. Report of the regional meeting on cholera and diarrhoeal diseases, Alexandria, 1-5 June 1978. 1978. Available from: https://apps.who.int/iris/handle/10665/254367.

18. World Health Organization, Regional Office for the Eastern Mediterranean. Report on the first meeting of the regional scientific working group on diarrhoeal diseases research, Alexandria, 19-22 August 1980. 1980. Available from: https:// apps.who.int/iris/handle/10665/254386.

19. Programme for Control of Diarrhoeal Diseases Interim Programme Report 1990. Geneva: World Health Organization; 1991. WHO document WHO/CDD/91.36.

20. GBD 2015 Eastern Mediterranean Region Diarrhea Collaborators. Burden of diarrhea in the Eastern Mediterranean Region, 1990-2015: Findings from the Global Burden of Disease 2015 study. Int J Public Health. 2018;63(Suppl 1):109-121. doi: 10.1007/s00038-017-1008-z.

21. Enzley S, Barros F, UNICEF NYHQ. A global review of diarrhoeal disease control. Available from: https://www. unicef.org/evaldatabase/index_14379.html.

22. World Health Organization, Regional Office for the Eastern Mediterranean. Report on the fifth meeting of the WHO regional advisory panel on cancer, Nicosia, 8-9 September 1980. 1981. Available from: https://apps.who.int/iris/ handle/10665/254408.

23. Yousefi Behzadi M, Mostafavi E. Marcel Balthazard: Adventurer of plague. 1st ed. Andishmand; 2015. [Persian].

24. World Health Organization, Regional Office for the Eastern Mediterranean. Seminar on the training and utilization of medical assistants, Khartoum, 16-20 December 1974. 1975. Available from: https://apps.who.int/iris/ handle/10665/254358

25. World Health Organization, Regional Office for the Eastern Mediterranean. Report on the group meeting on medical research in the Eastern Mediterranean Region, Alexandria, United Arab Republic, 22-26 February 1966. 1966. Available from: https://apps.who.int/iris/handle/10665/254328.

26. 26, Report on the seminar on health services in rural areas. Seminar on Health Services in Rural Areas; 1969: WHO. Eastern Mediterranean Region. Available from: http:// applications.emro.who.int/docs/EM_RH_14_EN.pdf.

27. World Health Organization, Regional Office for the Eastern Mediterranean. Report on the seminar on primary health care, Alexandria, 4-7 January 1978. 1978. Available from: https:// apps.who.int/iris/handle/10665/254370.

28. World Health Organization, Regional Office for the Eastern Mediterranean. Workshop on scientific approach to curriculum design, 30 July-14 August 1976. 1976. Available from: https://apps.who.int/iris/handle/10665/254359.

29. World Health Organization, Regional Office for the Eastern Mediterranean. Itinerant workshop on educational planning, November-December 1973, Alexandria, Khartoum, Addis Ababa. 1974. Available from: https://apps.who.int/iris/ handle/10665/254354.

30. World Health Organization, Regional Office for the Eastern Mediterranean. Report on the workshop on research management, Islamabad, 4-14 April, 1981. 1981. Available from: https://apps.who.int/iris/handle/10665/254413.

31. World Health Organization, Regional Office for the Eastern Mediterranean. Report on the inter-country workshop on MCH-FP teacher training programme, Barakat, 1-7 March 1981. 1981. Available from: https://apps.who.int/iris/ handle/10665/254412.

32. World Health Organization, Regional Office for the Eastern Mediterranean. Report on the nursing seminar, Tehran, Iran, 9 November-19 November 1966. 1966. Available from: https://applications.emro.who.int/docs/EM_NURS_149_ EN.pdf?_ga $=2.251989705 .1386591749 .1600718611$ 856891559.1592426813.

33. World Health Organization, Regional Office for the Eastern Mediterranean. Report on the seminar on the health needs of the pre-school child, Karachi, Pakistan, 26 February to 2 March 1968. 1968. Available from: https://apps.who.int/iris/ handle/10665/254330.

34. World Health Organization, Regional Office for the Eastern Mediterranean. Seminar on traditional practices affecting the health of women and children, Khartoum, 10-15 February 1979. 1979. Available from: https://apps.who.int/iris/ handle/10665/254379.

35. World Health Organization, Regional Office for the Eastern Mediterranean. Report of the seminar on expanded programme of immunization, Alexandria, 8-14 December 1977. 1978. Available from: https://apps.who.int/iris/ handle/10665/254368.

36. WHO. Mental health services in developing countries : papers presented at a $\mathrm{WHO}$ seminar on the organization of mental health services, Addis Ababa, 27 November to 4 December 1973. Available from: https://apps.who.int/iris/ handle/10665/37043.

37. Taba AH. Public health in the Eastern Mediterranean. Lancet. 1958;78(6):219-20.

38. Taba A. Who-Eastern-Mediterranean-region-trend of health education services. Int J Health Educ. 1967;10(4):158-66.

39. Taba A. 10 years of health progress in the Eastern Mediterranean Region. Int Nurs Rev. 1958;5(2):27.

40. Taba AH. A view of the World Health Organization Eastern Mediterranean Region. Acad Med. 1969;44(4):278-84.

41. Taba A. Shaping Future-Eastern Mediterranean Region. Who Chronicle. 1969;23(5):220.

42. Taba AH. World Health Organization. Regional Office for the Eastern Mediterranean (EMRO). Int Rehabil Med. 1981;3(2):110-1. doi: 10.3109/03790798109166749.

43. Taba $\mathrm{AH}$. The influence of irrigation on mankind. InArid Land Irrigation in Developing Countries 1977:433-5. doi: 10.1016/ B978-0-08-021588-4.50064-6.

44. Taba AH. Female circumcision. Trop Doct. 1980;10(1):21-3. doi: 10.1177/004947558001000110.

45. Taba AH. Problems of occupational carcinogenesis in developing countries. Cancer Detect Prev. 1981;4(1-4):25-30.

46. Taba AH. Nutritional problems in the weaning period: (report on a seminar in Addis Ababa, Ethiopia 3-15 March 1969). J Trop Pediatr. 1970;16(4):211-42. doi:10.1093/ tropej/16.4.211. 